\title{
Establishment of feline intestinal epithelial cell cultures for the propagation and study of feline enteric coronaviruses
}

Lowiese MB Desmarets, Sebastiaan Theuns, Dominique AJ Olyslaegers, Annelike Dedeurwaerder, Ben L Vermeulen, Inge DM Roukaerts and Hans J Nauwynck*

\begin{abstract}
Feline infectious peritonitis (FIP) is the most feared infectious cause of death in cats, induced by feline infectious peritonitis virus (FIPV). This coronavirus is a virulent mutant of the harmless, ubiquitous feline enteric coronavirus (FECV). To date, feline coronavirus (FCoV) research has been hampered by the lack of susceptible cell lines for the propagation of serotype I FCoVs. In this study, long-term feline intestinal epithelial cell cultures were established from primary ileocytes and colonocytes by simian virus 40 (SV40) T-antigen- and human Telomerase Reverse Transcriptase (hTERT)-induced immortalization. Subsequently, these cultures were evaluated for their usability in FCoV research. Firstly, the replication capacity of the serotype II strains WSU 79-1683 and WSU 79-1146 was studied in the continuous cultures as was done for the primary cultures. In accordance with the results obtained in primary cultures, FCoV WSU 79-1683 still replicated significantly more efficient compared to FCoV WSU 79-1146 in both continuous cultures. In addition, the cultures were inoculated with faecal suspensions from healthy cats and with faecal or tissue suspensions from FIP cats. The cultures were susceptible to infection with different serotype I enteric strains and two of these strains were further propagated. No infection was seen in cultures inoculated with FIPV tissue homogenates. In conclusion, a new reliable model for FCoV investigation and growth of enteric field strains was established. In contrast to FIPV strains, FECVs showed a clear tropism for intestinal epithelial cells, giving an explanation for the observation that FECV is the main pathotype circulating among cats.
\end{abstract}

\section{Introduction}

Feline coronaviruses (FCoVs) are associated with both enteric and systemic diseases in domestic and wild Felidae. The feline enteric coronavirus (FECV) is an ubiquitous enteropathogenic virus, replicating in epithelial cells of both small and large intestine after oral uptake [1-5]. The mild enteritis caused by this replication is usually unapparent or is manifested by a transient diarrhoea in young kittens [3]. Around 13\% of all infected cats are not able to clear the virus [6]. In these cats, the virus persists for several months or even years in the epithelium of the large intestine [2-5,7]. Since FECVs are easily transmitted from cat to cat by faecal-oral route, they are enzootic among most cat populations [3,8]. Although FECV-infections manifest subclinically, they may be the

\footnotetext{
*Correspondence: hans.nauwynck@ugent.be

Department of Virology, Parasitology and Immunology, Faculty of Veterinary Medicine, Ghent University, Salisburylaan 133, B-9820, Merelbeke, Belgium
}

start of a lethal outcome. During replication, mutations can occur in the viral genome, providing the virus with tools to productively replicate in monocytes/macrophages [9-12]. This mutational variant, designated feline infectious peritonitis virus (FIPV), causes a chronic and highly fatal systemic disease, FIP, characterized by a diffuse pyogranulomatous (peri)phlebitis and serositis in presence (wet form) or absence (dry form) of fibrinous exudate in the affected body cavities [13-15]. In contrast to FECV which is highly infectious but seldom causes disease, FIPV shows a low infectivity but high mortality (95-100\%) [16]. Losses from FIP are typically unpredictable and occur in only a restricted fraction $(<10 \%)$ of all seropositive cats [6,16-18]. However, the lack of tools to successfully prevent and control the disease has an enormous financial, emotional and ethical impact, and makes FIP the most feared infectious cause of death in cats [19]. To date, it remains unknown why FECV and 
FIPV show such a clinically (mild enteritis versus FIP) and epidemiologically (easy versus restricted transmission) different behaviour.

Besides the two pathotypes, FCoVs also occur as two serotypes [20]. Worldwide, the majority of all strains (both FECVs and FIPVs) are serotype I viruses [21-26]. In contrast to the type I viruses that are $100 \%$ feline, type II viruses possess spike and adjacent genes of canine origin since they have arisen by double recombination events between type I FCoVs and canine coronavirus (CCV) $[27,28]$. Despite their lower prevalence, most comparative in vitro studies have been performed with the easily cell culture growing serotype II strains WSU 79-1683 and WSU 79-1146 [9,10,12,29]. FCoV WSU 79-1146 has been shown to be a highly virulent, readily FIP-inducing virus due to its efficient infection of monocytes/macrophages. FCoV WSU 79-1683, on the other hand, is an avirulent virus, inducing at most a mild enteritis in kittens. The poor systemic dissemination of this virus has been attributed to a restricted, inefficient infection of monocytes/macrophages [9,10,12,30]. To date, cell culture propagation of the abundantly present serotype I FECVs has never been achieved and only few serotype I FIPV strains have been adapted to grow in felis catus whole fetus (fcwf) cells. However, most of these strains have lost their pathogenicity through cell culture adaptation [17,31]. Hence, comparative studies between non-culture adapted FECVs and FIPV have only been possible by comparing genomes of both naturally occurring strains [18,32-35]. To date, it remains unclear which genetic determinants make up a certain pathotype.

In the present study, cultures of intestinal epithelial cells from the ileum (ileocytes) and colon (colonocytes) were established by inducing a combined expression of SV40 T-antigen and hTERT in primary ileocytes and colonocytes. The reliability of these cultures for their use in $\mathrm{FCoV}$-research was first investigated by comparing replication capacities of the, at high titre available, avirulent FCoV WSU 79-1683 and the highly virulent FCoV WSU 79-1146 with results obtained for the primary cultures. Since those serotype II strains have been heavily cell culture adapted, the usability of the intestinal epithelial cell cultures in FCoV research was further evaluated by investigating their susceptibility for different field strains, present in faeces and tissues of coronavirusinfected cats.

\section{Materials and methods \\ Cats}

Since cats are euthanized every day in practice, tissues of these animals can be used in research in order to reduce the number of laboratory cats. Therefore, the intestines of euthanized conventional cats were used in this study and were a kind contribution to research by the owners.
This study was approved by the Local Ethical and Animal Welfare Committee of the Faculty of Veterinary Medicine of Ghent University (EC2012/043) and informed consent was obtained from all owners. Faecal extracts from SPF cats (Harlan laboratories, Indianapolis, IN, USA) experimentally infected with FECV UCD were used as a source of this enteric field strain. These infection experiments were approved by the Local Ethical and Animal Welfare Committee of the Faculty of Veterinary Medicine of Ghent University (EC2012/042).

\section{Isolation and cultivation of primary ileocytes and colonocytes}

Cats were sedated by intramuscular injection of a mixture of Ketamin $(0.05 \mathrm{~mL} / \mathrm{kg}$; Anesketin`, Eurovet, HeusdenZolder, Belgium) and Midazolam $\left(0.05 \mathrm{~mL} / \mathrm{kg}\right.$; Dormicum ${ }^{\circledR}$, Roche, Brussels, Belgium). Subsequently, the cats were euthanized by intracardial injection of $20 \%$ SodiumPentobarbital (1 mL/1.5 kg; Kela Laboratories, Hoogstraten, Belgium). The protocol used for the isolation of primary ileocytes and colonocytes was based on the one described by Rusu et al., with minor adaptations [36]. Directly after euthanasia, the ileum and colon were aseptically removed and transported in ice-cold Dulbecco's Modified Eagle Medium (DMEM; Gibco BRL, Merelbeke, Belgium) supplemented with $100 \mathrm{U} / \mathrm{mL}$ penicillin (Continental Pharma Inc., Puurs, Belgium), $0.1 \mathrm{mg} / \mathrm{mL}$ streptomycin (Certa, Braine l'Alleud, Belgium), $0.1 \mathrm{mg} / \mathrm{mL}$ gentamycine (Gibco BRL) and 10\% foetal bovine serum (FBS; Gibco BRL). Subsequently, the pieces of intestine were inverted, i.e. mucosal side facing outwards, and the intestinal content was removed by three vigorous washings in ice-cold DMEM supplemented with antibiotics. The intestinal mucosa was digested in DMEM containing collagenase I $(0.4 \mathrm{mg} / \mathrm{mL}$, Invitrogen, Paisley, UK) and dispase (1.2 mg/mL, Sigma, St. Louis, MO, USA) for $15 \mathrm{~min}$ (ileum) or $20 \mathrm{~min}$ (colon) at $37{ }^{\circ} \mathrm{C}$. Then, the digestion medium was refreshed and the pieces were incubated for another $45 \mathrm{~min}$ (ileum) or $60 \mathrm{~min}$ (colon) at $37{ }^{\circ} \mathrm{C}$. Subsequently, the pieces were longitudinally opened and the digested mucosa was scraped with a sterile scalpel blade. The scrapings were incubated in warm DMEM supplemented with antibiotics and dispase $(1.2 \mathrm{mg} / \mathrm{mL})$ for $10 \mathrm{~min}$ whilst pipetting. After centrifugation $(140 \times g, 3 \mathrm{~min})$ the pellet was resuspended in DMEM containing $2 \%$ D-Sorbitol (Sigma) and 10\% FBS, and centrifuged $(50 \times g, 3 \mathrm{~min})$ in order to separate as much single cells (most probably contaminating stromal cells) as possible from the epithelial cell clusters. This sorbitol centrifugation was repeated 5 times. The resulting pellet was subsequently resuspended 1:3 (vol:vol) in culture medium consisting of DMEM/F-12 supplemented with $100 \mathrm{U} / \mathrm{mL}$ penicillin, $0.1 \mathrm{mg} / \mathrm{mL}$ streptomycin and $0.1 \mathrm{mg} / \mathrm{mL}$ gentamycin, 10\% FBS (Gibco BRL), $10 \mathrm{ng} / \mathrm{mL}$ epidermal growth factor (Sigma), 1\% insulin-transferrin- 
selenuim-X (Invitrogen), 100 nM hydrocortisone (Sigma), $1 \%$ non-essential amino acids $100 \times$ (Gibco BRL), and $1 \mu \mathrm{g} / \mathrm{mL}$ 3,3',5-Triiodo-L-thyronine sodium salt (Sigma). The cells were seeded in 24-well plates or on glass coverslips coated with collagen type I (Roche Diagnostics, Vilvoorde, Belgium). The cells were cultivated in a $37{ }^{\circ} \mathrm{C} /$ $5 \% \mathrm{CO}_{2}$ atmosphere. After $24 \mathrm{~h}$, the culture medium was replaced by medium containing $2 \%$ FBS to restrict the outgrowth of non-epithelial cells. Medium was changed every other day. Morphological features of the primary cultures were evaluated every day by light microscopy (Olympus).

\section{Characterization of the primary cultures}

To assess the origin of the primary cells, doubleimmunostainings were performed against pancytokeratin and vimentin. Therefore, the cells were fixed with $4 \%$ paraformaldehyde in PBS for $10 \mathrm{~min}$ at room temperature (RT) followed by permeabilization with $0.1 \%$ Triton $\mathrm{X}-100$ for $2 \mathrm{~min}$ at RT. The cells were incubated with monoclonal anti-cytokeratin antibodies (Dako Denmark A/S) containing $10 \%$ normal goat serum for $1 \mathrm{~h}$ at $37{ }^{\circ} \mathrm{C}$, followed by goat anti-mouse-Texas Red labelled antibodies for $1 \mathrm{~h}$ at $37{ }^{\circ} \mathrm{C}$ (Molecular Probes, Eugene, Oregon, USA). Afterwards, the cells were incubated for $45 \mathrm{~min}$ at $37^{\circ} \mathrm{C}$ with monoclonal anti-vimentin antibodies (Lab Vision Corporation, Fremont, CA, USA) labelled with Zenon ${ }^{\oplus}$ Alexa Fluor 488 (Invitrogen) according to the manufacturer's protocol. Nuclei were stained with Hoechst 33342 (Molecular Probes) for $10 \mathrm{~min}$ at RT. The slides were mounted using glycerine-PBS solution (0.9:0.1, vol:vol) with 2.5\% 1,4-diazabicyclo[2.2.2] octane (Janssen Chimica, Beerse, Belgium) and analysed by fluorescence microscopy (DM B fluorescence microscope, Leica Microsystems GmbH, Heidelberg, Germany).

\section{Immortalization of primary feline ileocytes and colonocytes}

At 4 days post isolation, primary cultures of ileocytes and colonocytes from the same cat were transduced with both recombinant lentiviruses expressing either the SV40 large $\mathrm{T}$ antigen or the hTERT protein (Applied Biological Materials Inc., Canada) in addition of polybrene $(8 \mu \mathrm{g} / \mathrm{mL}$, Applied Biological Materials Inc.). After 30 min, medium was added and the cells were further incubated with the virus (1:1 vol:vol in medium) overnight. The following day, the viral supernatant was removed and cells were further incubated in medium. After 5 days, the cells were detached by trypsinization with $0.25 \%$ trypsin $0.02 \%$ EDTA, subcultured in collagen-coated wells (split ratio 1:2) and evaluated daily for clonal expansion by light microscopy (Olympus). Clusters of cells with epithelial (cobblestone-like) morphology were marked and other cells in the well were removed by scraping. Subsequently, the epithelial clusters were detached by trypsinization and further expanded in collagen-coated flasks to generate a long-term culture of both small and large intestinal epithelial cells.

\section{Characterization of the ileocyte and colonocyte cell lines}

To confirm the epithelial character of both cell lines, double-immunostainings were performed against cytokeratin and vimentin as described above. The success of transduction was assessed by performing immunocytochemical stainings against the SV 40 large T antigen and hTERT. Therefore, cells seeded on collagen-coated glass coverslips were fixed with $4 \%$ paraformaldehyde, followed by permeabilization with $0.1 \%$ Triton X-100. The cells were incubated with polyclonal rabbit antibodies against hTERT (Applied Biological Materials Inc.) containing 10\% normal goat serum for $1 \mathrm{~h}$ at $37{ }^{\circ} \mathrm{C}$, followed by goat ant-rabbitFITC labelled antibodies (Molecular Probes) for $1 \mathrm{~h}$ at $37^{\circ} \mathrm{C}$. Subsequently, the cells were incubated with monoclonal antibodies against the SV40 large $\mathrm{T}$ antigen (Applied Biological Materials Inc.) containing 10\% normal goat serum, followed by goat anti-mouse-AF594 labelled antibodies (Molecular Probes), each for $1 \mathrm{~h}$ at $37{ }^{\circ} \mathrm{C}$. Nuclei were stained and slides were mounted as described above. The cells were analysed by fluorescence microscopy (DM B fluorescence microscope, Leica Microsystems $\mathrm{GmbH}$ ). In addition, immunocytochemical stainings against the intestinal brush border hydrolase aminopeptidase $\mathrm{N}$ were performed. Therefore, cells were fixed with $1 \%$ paraformaldehyde and incubated with the monoclonal antibody R-G-4 (kindly provided by Dr Hohdatsu, Department of Veterinary Infectious Diseases, Towada, Japan) containing 10\% normal goat serum followed by goat anti-mouse-FITC labelled antibodies (Molecular Probes), each for $1 \mathrm{~h}$ at $37^{\circ} \mathrm{C}$. Images were obtained using a Leica TCS SPE laser scanning spectral confocal system linked to a DM B fluorescence microscope (Leica Microsystems). Argon and $\mathrm{He} / \mathrm{Ne}$ lasers were used for exciting FITC and Texas Red fluorochromes, respectively. Leica confocal software was used for image acquisition.

\section{Expression kinetics of viral antigens in FCoV WSU 79-1683 and FCoV 79-1146 infected cells}

A third passage of the FCoV strains 79-1683 and 79-1146 grown in Crandell feline kidney (CrFK) cells were used. FCoV WSU 79-1683 was obtained from the American Type Culture Collection (ATCC) and FCoV WSU 79-1146 was kindly provided by Dr Egberink (Department of Infectious Diseases and Immunology, Utrecht University, the Netherlands). At 4 days post isolation, primary cells of three cats were inoculated at a multiplicity of infection (moi) of 1 . After $1 \mathrm{~h}$ incubation $\left(37^{\circ} \mathrm{C}, 5 \%\right.$ $\mathrm{CO}_{2}$ ) the cells were washed 3 times with warm DMEM 
and further incubated in medium. Monolayers of continuous ileocyte and colonocyte cultures were inoculated in the same way. At different time points $(0,3,6,9,12$ and $24 \mathrm{~h}$ ) post inoculation, cells were fixed with $4 \%$ paraformaldehyde for $10 \mathrm{~min}$ and permeabilized with $0.1 \%$ Triton X-100 for 2 min at RT. For the primary cultures, double-immunostainings against both FCoV-antigens and cytokeratin were performed to visualize the infected epithelial cells. For the continuous cultures, only viral antigens were stained. Viral antigens were visualized with polyclonal FITC-labelled anti-FCoV antibodies (VMRD, Pullman, USA). Cytokeratin-positive cells were visualized as described above. Nuclei were stained with Hoechst, the slides were mounted and analysed by fluorescence microscopy (Leica Microsystems GmbH). All experiments were performed 3 times. The area under the curve was determined for each experiment. Triplicate assays were compared using a Mann-Whitney U test. Statistical analysis was performed using GraphPad Prism version 5.0c (GraphPad software, San Diego, CA, USA). $P$ values $\leq 0.05$ were considered significantly different.

Using primary cells of conventional cats holds the risk that cultured cells are already infected with FCoVs. Therefore, mock-infected cells were accurately screened to exclude the presence of inherent infected cells. All cells were negative for inherent coronavirus.

\section{One-step real time RT-PCR for the detection of the viral load in field strain suspensions}

RNA was extracted from the faecal suspensions using the QIAamp Viral RNA Mini Kit (Qiagen, Benelux BV, Belgium) and from tissue suspensions with the RNeasy Mini Kit (Qiagen). To avoid detection of subgenomic mRNA's, primers were designed using the Primer 3 plus software within a conserved region of ORF1b based on FCoV sequences available in GenBank. A $20 \mu \mathrm{L}$ PCR mixture was used per reaction and contained $10 \mu \mathrm{L}$ Precision OneStep $^{\text {tw }}$ qRT-PCR Mastermix with SYBR Green and ROX (PrimerDesign, Southampton, UK), $0.2 \mu \mathrm{M}$ forward primer ORF1bFW (5'-TGGACCATGAGCAAGT CTGTT-3'), 0.4 $\mu \mathrm{M}$ reverse primer ORF1bRV (5'-CAGATC CATCATTGTGTACTTTGTAAGA-3') and $3 \mu \mathrm{L}$ RNA or diluted standard RNA (see below). A reverse transcription step of $10 \mathrm{~min}$ at $55^{\circ} \mathrm{C}$ and an enzyme activation step at $95^{\circ} \mathrm{C}$ for $8 \mathrm{~min}$ were followed by 40 cycles, each $10 \mathrm{~s}$ at $95{ }^{\circ} \mathrm{C}$ and $60 \mathrm{~s}$ at $58{ }^{\circ} \mathrm{C}$. A first-derivative melting curve analysis was performed by heating the mixture to $95^{\circ} \mathrm{C}$ for $15 \mathrm{~s}$, then cooling to $60{ }^{\circ} \mathrm{C}$ for $1 \mathrm{~min}$, and heating back to $95{ }^{\circ} \mathrm{C}$ at $0.3{ }^{\circ} \mathrm{C}$ increments. Reverse transcription, amplification, monitoring, and melting curve analysis were carried out in a Step One Plus ${ }^{\text {Th }}$ real-time PCR system (Applied Biosystems, Life Technologies Corporation, Carlsbad, CA, USA).

\section{Synthetic RNA standards for absolute quantitation}

RNA was extracted from faecal suspensions containing FECV UCD using the QIAamp Viral RNA Mini Kit (Qiagen). The RNA was reverse-transcribed into cDNA using the SuperScript ${ }^{\mathrm{tm}}$ III First-Strand Synthesis System for RT-PCR (Invitrogen). Briefly, 250 ng RNA was incubated for $5 \mathrm{~min}$ at $65{ }^{\circ} \mathrm{C}$ with $2 \mu \mathrm{M}$ reverse primer ORF1bRV and $10 \mathrm{mM}$ dNTP mix. Afterwards, an equal volume of cDNA synthesis mix, containing $10 \times$ RT buffer, $25 \mathrm{mM} \mathrm{MgCl}_{2}, 0.1 \mathrm{M}$ DTT, $40 \mathrm{U} / \mu \mathrm{l}$ RNase OUT and $200 \mathrm{U} / \mu \mathrm{L}$ Superscript III RT was added and incubated for $50 \mathrm{~min}$ at $50{ }^{\circ} \mathrm{C}$. The reaction was terminated at $85{ }^{\circ} \mathrm{C}$ for $5 \mathrm{~min}$. RNA was removed by incubation with RNase $\mathrm{H}$ for $20 \mathrm{~min}$ at $37^{\circ} \mathrm{C}$. The $50 \mu \mathrm{L}$ PCR mixture for the amplification of the cDNA contained $10 \mu \mathrm{L} 5 \times$ Herculase II reaction buffer, $0.8 \mu \mathrm{L}$ dNTP mix, $2 \mu \mathrm{L}$ DNA template, $0.25 \mu \mathrm{M}$ forward primer ORF1bFW modified with a T7 promoter sequence at its 5' end (5'- TAATACGACTCACTATAGGG TGGACC ATGAGCAAGTCTGTT-3'), $0.25 \mu \mathrm{M}$ reverse primer ORF1bRV, and $1 \mu \mathrm{L}$ Herculase II fusion DNA polymerase (Agilent Technologies Inc., Santa Clara, CA, USA). After a denaturation step for $1 \mathrm{~min}$ at $95^{\circ} \mathrm{C}, 30$ cycles of amplification, each $20 \mathrm{~s}$ at $95{ }^{\circ} \mathrm{C}, 20 \mathrm{~s}$ at $50{ }^{\circ} \mathrm{C}$, and $60 \mathrm{~s}$ at $68{ }^{\circ} \mathrm{C}$, were followed by a terminal elongation of $4 \mathrm{~min}$ at $68{ }^{\circ} \mathrm{C}$. Fragment length was controlled by agarose gel electrophoresis and fragments with the correct length were excised and purified from the gel using the Nucleospin ${ }^{\circ}$ Gel and PCR Clean-up kit (Macherey-Nagel, Düren, Germany). cRNA standards were transcribed by incubation for $1 \mathrm{~h}$ at $37^{\circ} \mathrm{C}$ with $10 \times$ transcription buffer, $500 \mu \mathrm{M}$ rNTPs and $20 \mathrm{U}$ T7 RNA polymerase-Plus Enzyme Mix (Applied Biosystems). Transcription reactions were DNase I treated and the amount of RNA was determined using the Nanodrop 2000 system. Ten-fold serial dilutions of the RNA were made over a range of $6 \log$ units $\left(10^{7}-10^{2}\right)$ for the generation of the standard curve (Efficiency: $93.96 \pm 0.76 \% ; R^{2}: 0.999$ ).

\section{Assessment of the infectious coronavirus titre in faecal and tissue suspensions}

Faecal samples were collected from healthy cats housed in 3 different catteries / multi-cat environments that have dealt with FIP in the past. Faecal extracts of experimentally infected cats containing an unknown titre of FECV strain UCD (originally isolated at UC Davis, [3]) were a kind gift of Dr Rottier (Department of Infectious Diseases and Immunology, Utrecht University, the Netherlands). This suspension was clarified by centrifugation at $4000 \times g$ for $10 \mathrm{~min}$ and SPF cats were infected with the supernatant. Faecal extracts from one cat were used as a source of this enteric field strain. From all faecal samples, 20\% suspensions were made in DMEM supplemented with 2\% FBS (Gibco, BRL), $100 \mathrm{U} / \mathrm{mL}$ penicillin (Continental 
Pharma Inc.), $0.1 \mathrm{mg} / \mathrm{mL}$ streptomycin (Certa), and $0.1 \mathrm{mg} / \mathrm{mL}$ gentamycin (Gibco BRL). From 4 cats with FIP (immunohistochemically confirmed), faeces and affected tissues were collected. From tissue homogenates, 20\% suspensions were made in DMEM supplemented with $100 \mathrm{U} / \mathrm{mL}$ penicillin (Continental Pharma Inc.), $0.1 \mathrm{mg} / \mathrm{mL}$ streptomycin (Certa), and $0.1 \mathrm{mg} / \mathrm{mL}$ gentamycin (Gibco $\mathrm{BRL})$. Suspensions were centrifuged $\left(1200 \times g, 4{ }^{\circ} \mathrm{C}, 20 \mathrm{~min}\right)$, and the supernatant was aliquoted and stored at $-70{ }^{\circ} \mathrm{C}$ until use. All samples were initially screened by immunofluorescence in both cell lines by inoculating monolayers, seeded on collagen coated coverslips, with $250 \mu \mathrm{L}$ of the suspensions for $1 \mathrm{~h}$ at $37{ }^{\circ} \mathrm{C}$. Thereafter, cells were washed and further incubated in medium for $24 \mathrm{~h}$. After fixation and permeablization, infected cells were visualized as described above. In addition, the amount of infectious virus was quantified in all samples, including the initially negative ones. Therefore, monolayers of colonocytes, seeded in collagen I coated 96well plates, were inoculated with $50 \mu \mathrm{L}$ of serially diluted $(1 / 10)$ faecal or tissue suspensions (ranging from $10^{0}$ to $10^{-}$ $\left.{ }^{7}\right)$. After $1 \mathrm{~h}\left(37^{\circ} \mathrm{C}, 5 \% \mathrm{CO}_{2}\right)$, medium was added and the cells were further incubated for $72 \mathrm{~h}$. To reduce cell loss due to toxicity, undiluted suspensions were removed from the wells $1 \mathrm{~h}$ post inoculation (pi), the cells were washed 2 times and further incubated in medium for $72 \mathrm{~h}$. Then, plates were washed with PBS, air-dried $\left(1 \mathrm{~h}, 37^{\circ} \mathrm{C}\right)$ and frozen $\left(-20^{\circ} \mathrm{C}\right)$. The $50 \%$ tissue culture infectious dose $\left(\mathrm{TCID}_{50}\right)$ was determined by means of immunoperoxidase monolayer assay (IPMA). Therefore, cells were fixed and permeabilized by incubation with PF 4\% (10 min, RT), followed by incubation with methanol containing $1 \% \mathrm{H}_{2} \mathrm{O}_{2}$ (5 min, RT). Then, cells were incubated with PBS containing 10\% normal goat serum and $0.1 \%$ Tween 80 for $30 \mathrm{~min}$ at $37{ }^{\circ} \mathrm{C}$. Subsequently, cells were incubated with monoclonal antibodies against the $\mathrm{N}$-protein (produced and characterized in the laboratory of the authors), followed by incubation with goat anti-mouse HRP-labelled antibodies. Infected cells were visualized by adding sodium-acetate buffer containing amino-ethylcarbazola (AEC) and $\mathrm{H}_{2} \mathrm{O}_{2}$ for $10 \mathrm{~min}$ at RT. The fifty percent end-point was calculated according to the method of Reed and Muench [37]. The serotype of all samples was determined by means of RTPCR described by Addie et al. [22].

\section{Determination of infectious virus in FIPV-suspensions by inoculation of monocyte-derived macrophages}

Feline monocytes were isolated and seeded on glass coverslips as previously described [10]. At 7 days post seeding, cells were inoculated with $250 \mu \mathrm{L}$ of the suspensions. After $1 \mathrm{~h}$ at $37{ }^{\circ} \mathrm{C}$, cells were washed and further incubated in medium for $24 \mathrm{~h}$. After fixation and permeabilization, infected cells were visualized by immunofluorescence staining as described above.

\section{Propagation and titration of FECV UCD and UG-FH8}

Two different faecal strains, UCD and UG-FH8, were passaged 3 times in continuous colonocyte cultures, starting from the faecal suspensions. After 3 passages, the $\mathrm{TCID}_{50}$ was determined as described above. In addition, sequencing of ORF3 and ORF7 was performed to check for their integrity. Therefore, primers were designed using published sequences of FCoV ORF3 and ORF7 in GenBank. Viral RNA was extracted from the faecal suspensions with the QIAamp Viral RNA Mini Kit (Qiagen) and cDNA was generated using SuperScript ${ }^{\mathrm{Tm}}$ III First-Strand Synthesis System for RT-PCR (Invitrogen). Amplification was carried out in a $50 \mu \mathrm{L}$ reaction using Herculase II fusion DNA polymerase (Agilent Technologies Inc., Santa Clara, CA, USA). The Nucleospin ${ }^{\ominus}$ Gel and PCR Clean-up kit (Macherey-Nagel) was used for purification of the PCR products. Sequencing was performed by the GATC Biotech Company (Konstanz, Germany). Additionally, it was investigated if both third passage strains still showed a specific enterotropism by inoculating other feline cell lines (CrFK and fcwf cells). 24 h pi, infected cells were visualized by immunofluorescence staining as described above.

\section{Results \\ Morphological features and characterization of the primary cultures}

By using a combination of dispase and collagenase, epithelial cells were isolated from the underlying basement membrane in clusters (Figure 1A). Four hours post seeding, the majority of the cells had attached and foci of polygonal cells became visible within $24 \mathrm{~h}$ post seeding (Figure 1B, 1D). Primary ileum cultures were always "contaminated" with a lot of elongated or stellate-like cells, present in between the epithelial foci, while the colon cultures were more pure. For the ileum, the epithelial cells did not further grow beyond $24 \mathrm{~h}$ post seeding, whereas mesenchymal cells started to expand in between the epithelial cell clusters. In the colonic cultures, the epithelial cells showed a confined proliferation within 3-4 days post isolation, resulting in the formation of (sub)confluent cobblestonelike layers (Figure 1E). Then, these cells had reached a state of replicative senescence, which became typically characterized by morphological changes such as increase in cell size and development of multiple nuclei at 6-7 days post isolation. The growth arrest seemed not to be the result of the confluent state since, despite many attempts, it was not possible to subculture the cells. A part of the cells started to degenerate from 7 days post seeding. However, most of the cells could be kept for another week. To prevent cell loss due to inherent degeneration and to prevent overgrowth by mesenchymal cells, both ileum and colon cultures were always infected at 4 days post isolation for studying the viral replication. 

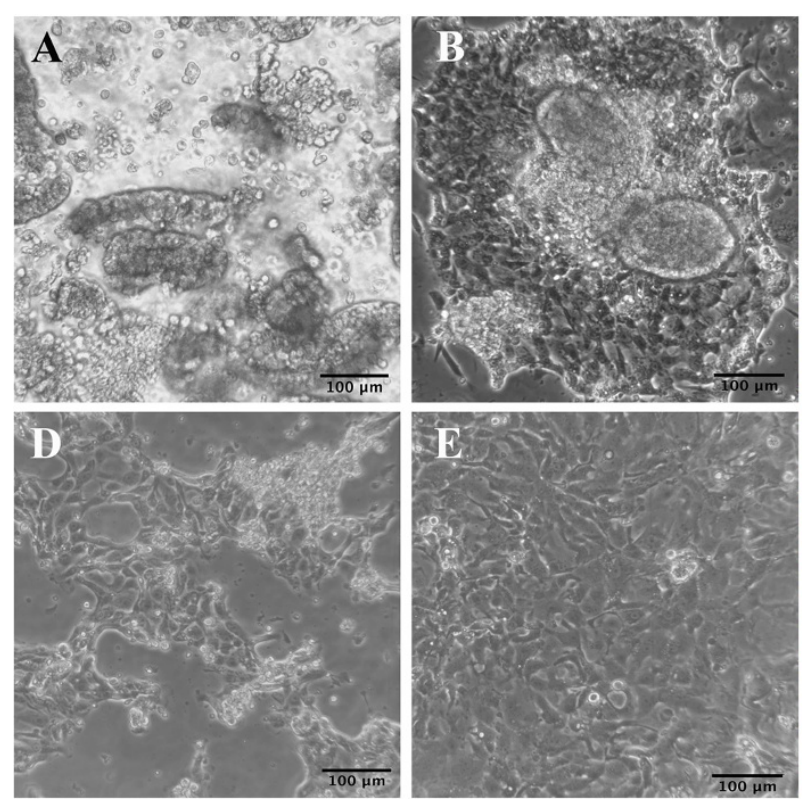
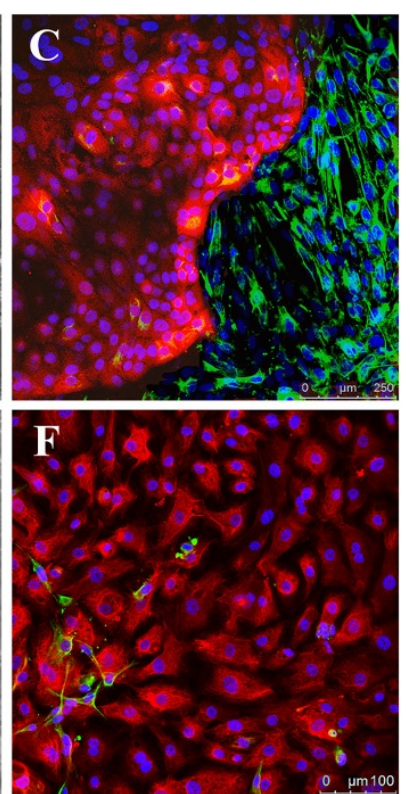

Figure 1 Morphological features and immunocytochemical characterization of the primary ileum (A-C) and colon (D-F) cultures. (A) Epithelial cells were isolated in cell clusters. (B, D) Polygonal cells started to spread from these clusters giving rise to several foci of cells. (E) (Sub) confluent layers were reached 3-4 days after seeding due to a restricted proliferation of the cells. (C, F) Double-immunostainings against cytokeratin (red) and vimentin (green) filaments 4 days after isolation, confirming the epithelial nature of the polygonal cells.

Immunofluorescence stainings against cytokeratin (intermediate filaments typically found in the cytoskeleton of epithelial cells) and vimentin (intermediate filaments expressed by mesenchymal cells) confirmed the epithelial nature of the polygonal, cobblestone-like cells
(Figure 1C, 1F). At 4 days post isolation, the majority of the cells $(>90 \%)$ in the colon cultures was still of epithelial origin. For the ileum cultures, the vimentin positive mesenchymal cells had expanded in between the epithelial clusters, occupying around $50 \%$ of the wells. Remarkably,
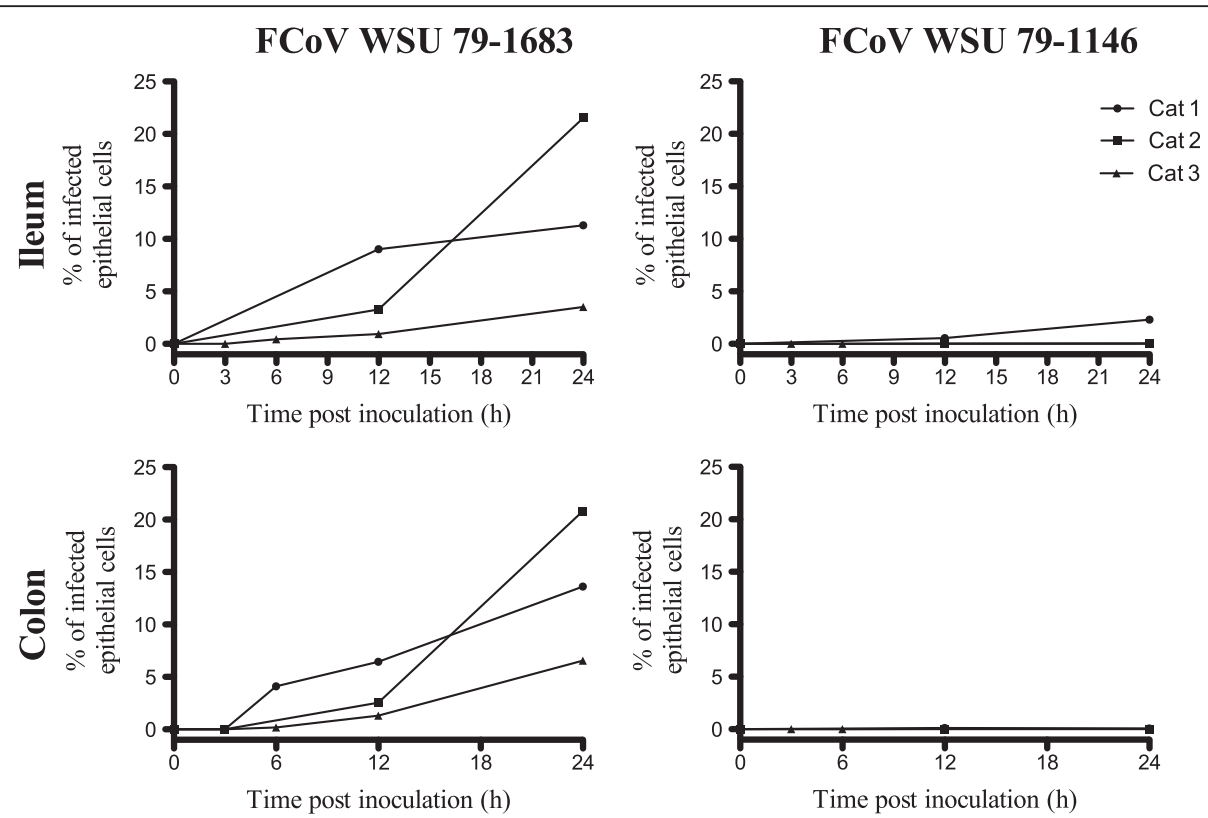

Figure 2 Kinetics of FCoV replication in primary ileum and colon cultures from $\mathbf{3}$ conventional cats. Cells were inoculated with FCoV WSU 79-1683 or FCoV WSU 79-1146 at a moi = 1. At different time points post inoculation, cytoplasmically expressed viral proteins were visualized and the percentage of infected epithelial cells was determined. 
some of the ileum epithelial cells did also express vimentin, resembling dedifferentiated epithelial cells typically found after injury or in tumours (Figure 1C).

\section{Expression kinetics of viral antigens in FCoV WSU 79-1683} and WSU 79-1146-infected primary ileocytes and colonocytes Primary ileocytes and colonocytes were susceptible to infection with both serotype II FCoV strains. However, the antigen expression kinetics differed greatly between the avirulent FCoV WSU 79-1683 and the virulent FCoV WSU 79-1146 (Figure 2). For both strains, the first antigenpositive cells appeared at $6 \mathrm{~h}$ pi and increased further over time. However, the avirulent enterotropic WSU 79-1683 strain infected the cells significantly more efficient $(P=0.05$ for both ileum and colon) compared to WSU 79-1146.

\section{Morphological features and characterization of the} established continuous ileocyte and colonocyte cultures By introducing a combinational expression of SV40 large T-antigen and hTERT, a successfully transformed cell line was generated for both ileocytes and colonocytes (Figures 3 and 4). Indeed, a various number of the transduced cells started to proliferate from 1 week after transduction onwards, forming layers of cobblestone-like cells with a cell diameter of $20-25 \mu \mathrm{m}$ and 30-35 $\mu \mathrm{m}$ for ileocytes and colonocytes, respectively. Both SV40 large T-antigen as hTERT expression was detected in these cultures, confirming the success of transduction. These cell lines could be further expanded and passaged for over 30 passages now, which is in sharp contrast to the primary cultures. Besides its typical cobblestone-like appearance, the epithelial character was confirmed by the expression of cytokeratin and dome formation in the cultures. The latter is indicative for the polarization of cells in monolayers. Remarkably, most of the cells in both cultures co-expressed both cytokeratin and vimentin in the freshly formed monolayers, suggesting a more dedifferentiated state of the cells. For further characterization, APN expression in the cultures was investigated, since APN is an intestinal brush border associated hydrolase, and moreover an important receptor for serotype
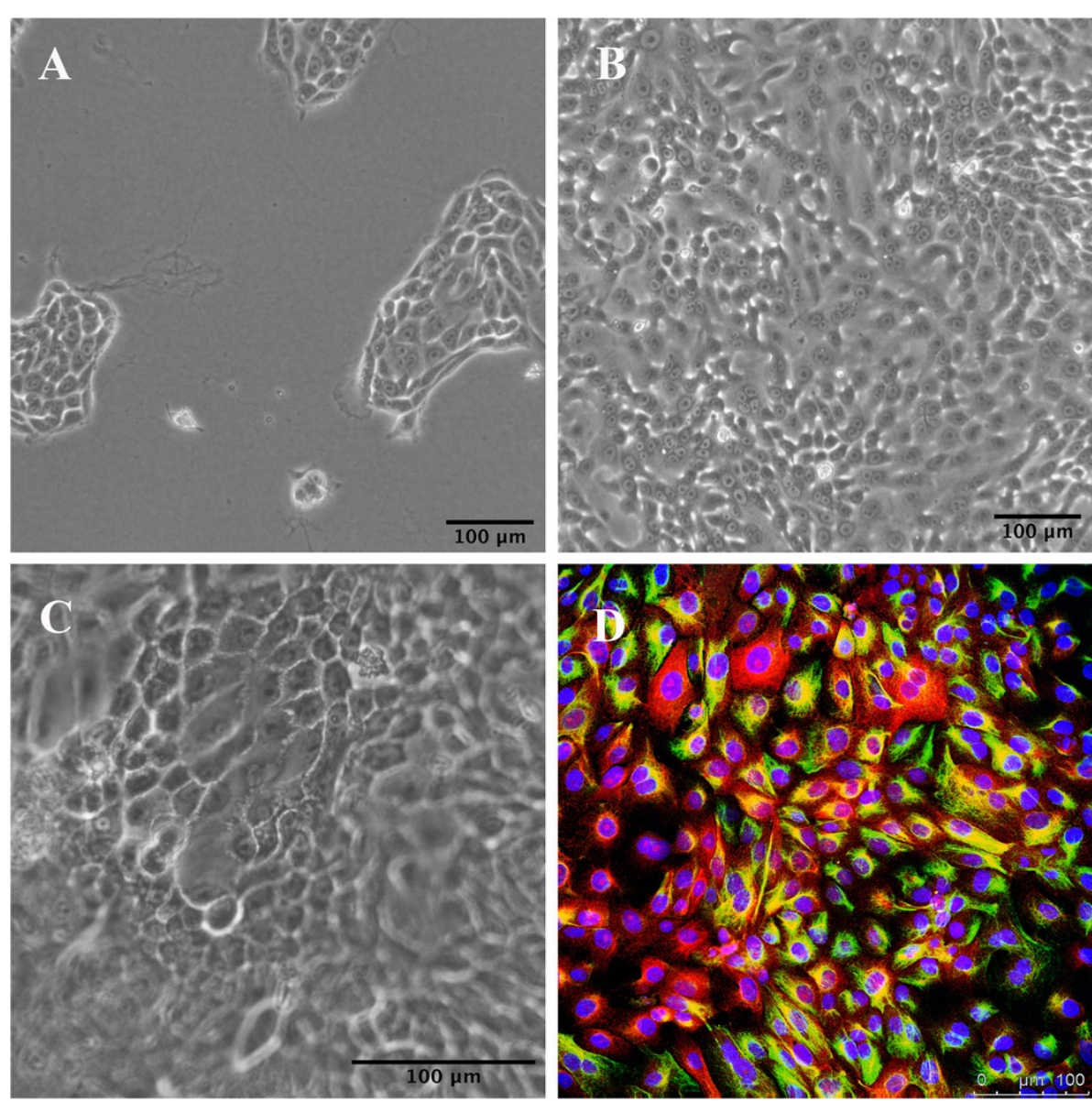

Figure 3 Morphological and immunocytochemical characterization of the continuous ileocyte cultures. (A) Proliferating isles. (B) Cobblestone morphology of the monolayer. (C) Dome formation. (D) Double-immunostaining against cytokeratin (red) and vimentin (green) filaments. 

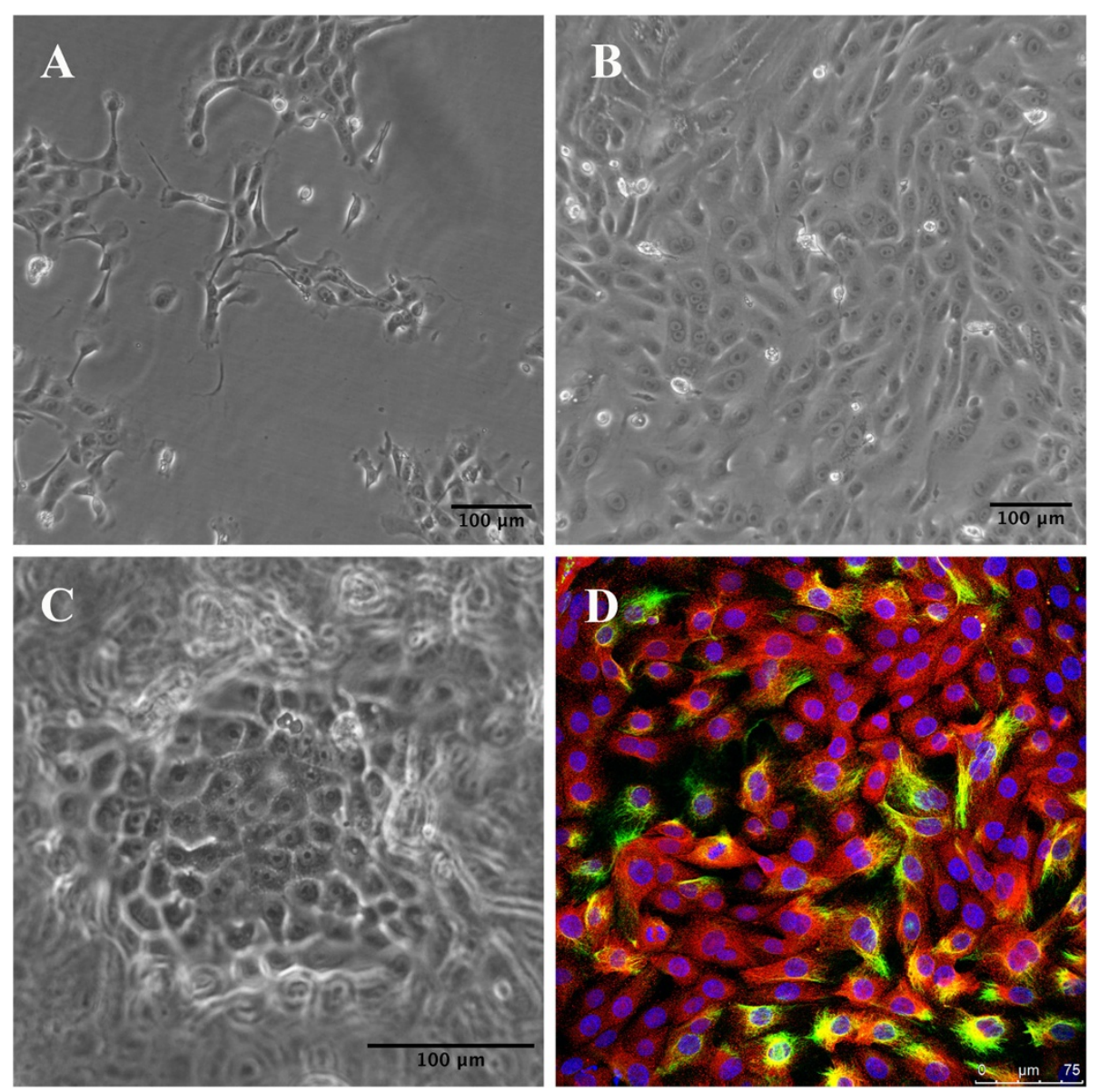

Figure 4 Morphological and immunocytochemical characterization of the continuous colonocyte cultures. (A) Proliferating isles. (B) Cobblestone morphology of the monolayer. (C) Dome formation. (D) Double-immunostaining against cytokeratin (red) and vimentin (green) filaments.

II FCoVs. All cells expressed APN at their surface. However, the expression levels varied great from cell to cell in both cultures, most probably due to different differentiation levels of the cells in culture.

\section{Antigen expression kinetics of FCoV WSU 79-1683 and WSU 79-1146 in continuous ileocyte and colonocyte cultures}

Since the continuous cultures seemed to be less differentiated compared to the primary cultures, the reliability of the established cell lines as model for intestinal epithelial cells was further investigated. Therefore, antigen expression kinetics were assessed in both continuous ileocyte and colonocyte cultures as was done for the primary cells (Figure 5). In accordance with the results obtained for the primary cultures, FCoV WSU 79-1683 significantly infected both ileocytes as colonocytes more efficiently than WSU 79-1146. At $24 \mathrm{~h}$ pi, FCoV WSU $79-1683$ had infected $19.46 \pm 4.37 \%$ and $18.47 \pm 4.61 \%$ of the colonocytes and ileocytes, respectively, whereas only $0.03 \pm 0.02 \%$ of the colonocytes and $0.22 \pm 0.18 \%$ of the ileocytes were infected by FCoV WSU 79-1146 at that time point.

\section{Titration of field strains in faecal and tissue suspensions}

A major restriction in FCoV research is the lack of cell lines supporting the growth of serotype I enteric strains. Therefore, the newly established cell lines were further validated by investigating their susceptibility for different field strains. All those strains were serotype I viruses as confirmed by PCR. Table 1 gives the results obtained by titration of different faecal and tissue suspensions on colonocyte cultures. Comparable results were obtained by titration on ileocyte cultures with FECV UCD. Hence, titration of other field strains was not repeated on this cell line. All but two of the samples collected from healthy cats were positive for coronavirus, with qPCR titres ranging from $10^{4.18}$ to $10^{9.06}$ viral copies / g faeces. Infectious virus was detected by IPMA in $50 \%$ of all positive samples $(8 / 16)$, with $57 \%$ of positivity in samples with qPCR titres above $10^{5}$. This number increased to $64 \%$ $(7 / 11)$ and $80 \%(4 / 5)$ when the cutoff was made at qPCR 
FCoV WSU 79-1683
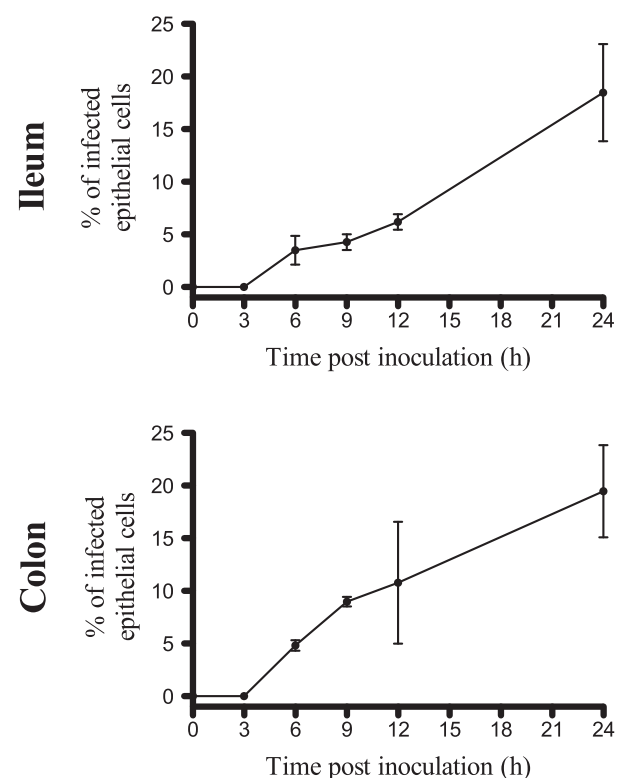

FCoV WSU 79-1146
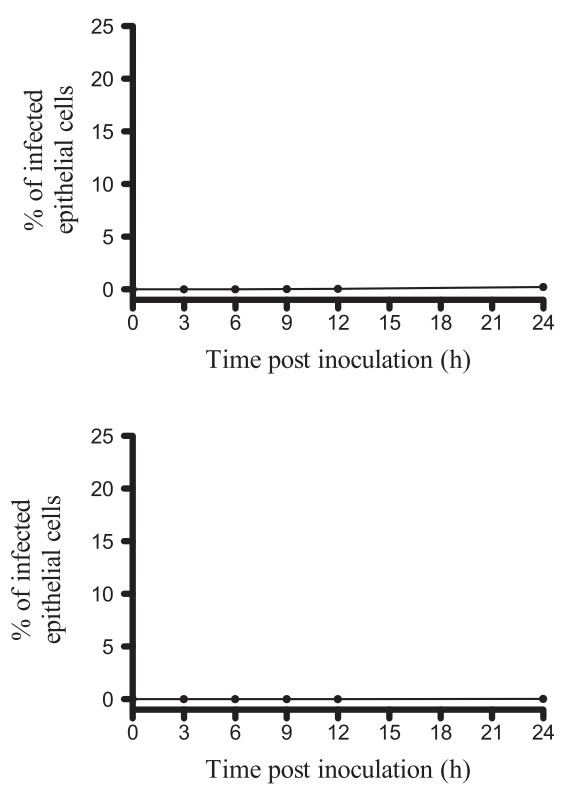

Figure 5 Kinetics of FCoV replication in continuous ileocyte and colonocyte cultures. Cells were inoculated with FCoV WSU 79-1683 or FCoV WSU 79-1146 at a moi=1. At different time points post inoculation, the percentage of infected cells was determined. Data are expressed as the means \pm standard deviation of the results of 3 separate experiments.

titres above $10^{6}$ and $10^{7}$ viral copies / $\mathrm{g}$ faeces, respectively. In the one sample (UG-FH9) with a qPCR above $10^{7}$ that was negative on IPMA, enterotropic virus was detected by immunofluorescence staining. All but one of the samples collected from FIP cats were positive for coronavirus on $\mathrm{qPCR}$, with the number of viral copies / $\mathrm{g}$ ranging from $10^{3.98}$ to $10^{9.16}$. As determined by both IPMA and immunofluorescence staining, none of those samples, except for one, contained enterotropic virus. However, 3 tissue samples (UG-TF5, UG-TF9 and UG-TF17) did contain infectious virus as determined on monocytederived macrophages. Despite its high viral load, no infectious virus (neither on enterocytes nor on monocytes/ macrophages) was found in faecal suspensions of FIP cat 1 (UG-FF1). Faeces of FIP cat 2 (UG-FF2) did contain enterotropic virus that was not infectious for macrophages.

\section{Propagation and titration of FECV UCD and UG-FH8}

To date, no serotype I enteric field strains have been propagated in vitro and availability of such FECV strains would be valuable in feline coronavirus research. Therefore, two faecal strains, FECV UCD and UG-FH8, were further propagated in colonocyte cultures (Table 2). After 3 passages, both strains were raised in titre with around $3 \log _{10} \mathrm{TCID}_{50} / \mathrm{mL}$. In addition, ORF3 and ORF7 from each of the third passage strains were sequenced to check for signs of cell culture adaption. Both strains still carried intact accessory genes that were 100\% identical to the original strain. Typically, a lot more CPE was noticed in UG-FH8 infected wells compared to FECV UCD (Figure 6). After 3 passages, both strains still showed a specific enterotropism, since no infection was seen after inoculation of other feline cell lines (fcwf and CrFK cells).

\section{Discussion}

In this study, immortalized cultures of both small (ileum) and large (colon) intestinal epithelial cells were established and validated for their use in feline coronavirus research. Intestinal epithelial cells are important target cells in FCoV pathogenesis but to date such cell lines are not available. The establishment of primary intestinal epithelial cell cultures has been proven to be difficult because of the induction of programmed cell death after disruption from the extracellular matrix, the uncontrolled contamination with stromal cells and the still unknown homeostatic components needed for the maintenance of these cultures [38]. To avoid induction of apoptotic signals by disrupting cell-matrix adhesions, a combination of collagenase and dispase was used in this study to digest the mucosa, allowing the isolation of epithelial cell clusters. These were subsequently separated as much as possible from the contaminating single stromal cells by D-sorbitol density centrifugation. The primary colon cultures showed a relative high purity of epithelial cells, whereas primary ileum cultures were much more contaminated with stromal cells. The contamination with mesenchymal cells is intrinsic to the isolation method used and therefore inevitable. Yet, the epithelial cells 
Table 1 QPCR- and infectious titre of different faecal and tissue suspensions from healthy and FIP cats

\begin{tabular}{|c|c|c|c|}
\hline Sample & Source & $\begin{array}{c}\text { QPCR titre } \\
\left(\log _{10} \text { copies / g) }\right.\end{array}$ & $\begin{array}{c}\text { Infectious titre } \\
\left(\log _{10} \mathrm{TCID}_{50} / \mathrm{g}\right)\end{array}$ \\
\hline UG-FH1 & Faeces healthy cats & 6.03 & - \\
\hline UG-FH2 & Faeces healthy cats & 6.64 & 2.67 \\
\hline UG-FH3 & Faeces healthy cats & 5.51 & - \\
\hline UG-FH4 & Faeces healthy cats & 5.41 & 2.36 \\
\hline UG-FH5 & Faeces healthy cats & 7.22 & 2.50 \\
\hline UG-FH6 & Faeces healthy cat & 6.88 & - \\
\hline UG-FH7 & Faeces healthy cat & - & - \\
\hline UG-FH8 & Faeces healthy cat & 6.30 & 3.33 \\
\hline UG-FH9 & Faeces healthy cats & 7.69 & - \\
\hline UG-FH10 & Faeces healthy cat & 7.89 & 2.50 \\
\hline UG-FH11 & Faeces healthy cats & 8.44 & 2.67 \\
\hline UG-FH12 & Faeces healthy cats & 4.66 & - \\
\hline UG-FH13 & Faeces healthy cats & - & - \\
\hline UG-FH14 & Faeces healthy cats & 6.27 & - \\
\hline UG-FH15 & Faeces healthy cat & 6.62 & 2.50 \\
\hline UG-FH16 & Faeces healthy cats & 4.18 & - \\
\hline FECV UCD & Faeces healthy cat $6 \mathrm{~d}$ pi & 9.06 & 5.00 \\
\hline UG-FF1 & Faeces FIP cat 1 & 7.57 & - \\
\hline UG-FF2 & Faeces FIP cat 2 & 9.16 & 3.50 \\
\hline UG-FF3 & Faeces FIP cat 3 & - & - \\
\hline UG-FF4 & Faeces FIP cat 4 & 3.98 & - \\
\hline UG-TF2 & Kidney FIP cat 1 & 6.79 & - \\
\hline UG-TF5 & Omentum FIP cat 2 & 6.87 & - \\
\hline UG-TF9 & Spleen FIP cat 3 & 5.83 & - \\
\hline UG-TF17 & Omentum FIP cat 4 & 8.00 & - \\
\hline
\end{tabular}

could be cultured for a week without overgrowth by these cells, making both primary cultures ideal models for studying interactions with enterotropic infectious agents. Remarkably, some primary cells co-expressed cytokeratin and vimentin filaments, which is often found in injured epithelial cells, tumours and in primary cultures due to the detachment of the cells from their natural environment during isolation. In these cells, the epithelial differentiation is turned back to a more embryonic state, amongst others characterized by de novo expression of vimentin filaments [39]. Only a minority of the cells did express vimentin, suggesting that most cells were able

Table 2 Infectious titre and status of ORF3 and ORF7 in cell culture propagated viruses

\begin{tabular}{|c|c|c|c|c|}
\hline \multirow[t]{2}{*}{ Strain } & \multicolumn{2}{|c|}{$\begin{array}{c}\text { Infectious titre } \\
\left(\log _{10} \mathrm{TCID}_{50} / \mathrm{mL}\right)\end{array}$} & \multirow[t]{2}{*}{$\begin{array}{c}\text { Status } \\
\text { ORF3 at } P_{3}\end{array}$} & \multirow[t]{2}{*}{$\begin{array}{c}\text { Status } \\
\text { ORF7 at } P_{3}\end{array}$} \\
\hline & $P_{0}$ & $P_{3}$ & & \\
\hline FECV UCD & 3.97 & 6.30 & Intact & Intact \\
\hline UG-FH8 & 2.63 & 5.97 & Intact & Intact \\
\hline
\end{tabular}

to restore their differentiation with the used culture conditions.

Although the doubtful origin and clear signs of cell culture adaptation [17,40], FCoV WSU 79-1683 and FCoV WSU 79-1146 were the only available strains representing an avirulent and related virulent strain at that time of the study. Hence, those strains were initially used for investigating the susceptibility of primary enterocytes to both virulent and avirulent FCoVs. Replication of both strains have been studied in CrFK cells, fcwf cells, peritoneal macrophages, bone marrow-derived macrophages and peripheral blood monocytes $[9,10,12,29]$. In contrast to the available continuous cultures (CrFK and fcwf cells), the difference in virulence between both strains was reflected in vitro when using primary FIPV target cells (monocytes/macrophages). The highly efficient and mostly sustained infection of FIPV in macrophages and monocytes from susceptible cats, in contrast to an inefficient and not sustained infection of the avirulent WSU 79-1683 in those cells, may explain why FIPV behaves as a harmful invasive virus causing this progressive 

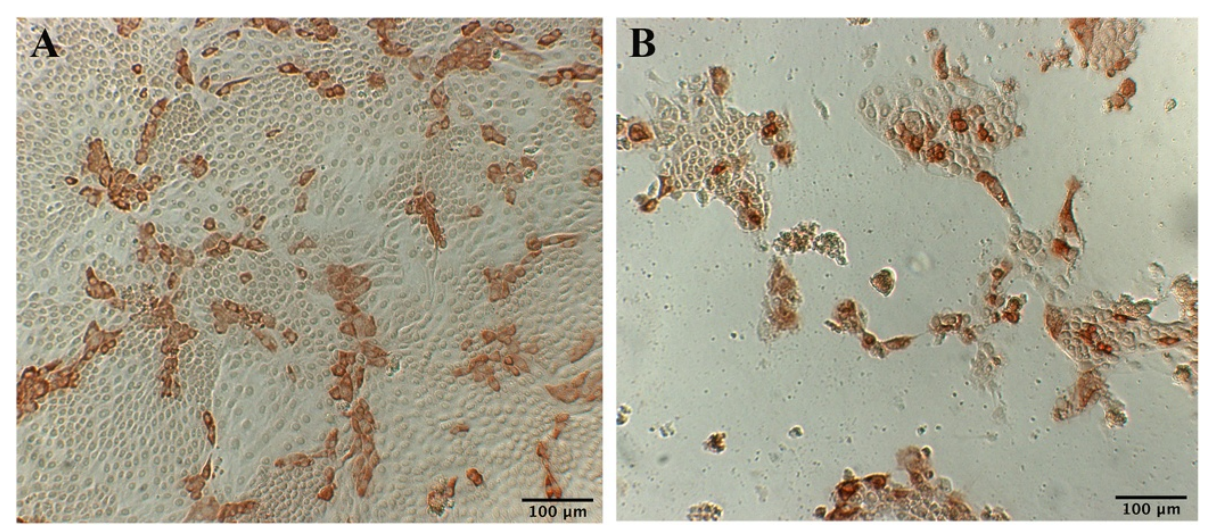

Figure 6 Immunoperoxidase staining of infected colonocytes. Infected colonocytes 3 days pi with (A) $10^{2.99} \mathrm{TCID}_{50}$ FECV UCD and (B) $10^{2.67} \mathrm{TCID}_{50} \cup \mathrm{G}-\mathrm{FH} 8$.

systemic disease $[9,10,12]$. As was previously shown for monocytes/macrophages, the present study confirms that both strains exhibit clear differences in cell tropism. In contrast to FCoV WSU 79-1146, the avirulent WSU 79-1683 efficiently infected and replicated in intestinal epithelial cells, resulting in exactly opposing kinetics as were found for macrophages [9].

Primary cultures are ideal tools to reliably investigate virus-host interactions. Nevertheless, isolation of primary epithelial cells is labour-intensive, the cultures are often contaminated with a various amount of mesenchymal cells and the yield is variable and rather low. To activate research with those cells, long-term cultures were derived from both primary ileocytes and colonocytes by SV40 T-antigen- and hTERT-induced immortalization, resulting in the generation of two feline intestinal epithelial cell cultures. The epithelial nature of both cell lines was confirmed by their cobblestone morphology, dome formation and cytokeratin expression. These newly established cell lines could be valuable tools for virus research. However, immortalized cell lines are often phenotypically transformed, making reliable research with these cells questionable. In the present study it was shown that, in contrast to the primary cultures, the majority of the cells co-expressed cytokeratin and vimentin filaments, suggesting that the cultures were less differentiated compared to their primary counterparts. Therefore, the reliability of the established cell lines for their use in feline coronavirus research was further investigated and confirmed. Antigen expression kinetics of FCoV WSU 79-1683 and FCoV WSU 79-1146 were comparable with the results obtained with the primary cultures, showing a significant difference in cell tropism between both strains. As mentioned before, comparative studies in the available continuous feline cell lines (CrFK and Fcwf cells) showed no replicative differences between both serotype II strains $[9,10,29]$. However, both cultures are hardly sensitive to serotype I FCoVs. To date, cultivation of serotype I FECVs has never been achieved and only few serotype I FIPV strains could be adapted to grow in continuous cell cultures. In addition, most of these strains seem to have lost their pathogenicity through cell culture adaptation $[17,31]$. In the present study, the newly established intestinal epithelial cell cultures were further evaluated for their susceptibility to serotype I field strains. Infectious, enterotropic virus was found in 57\% (8/14) of all FCoV-positive faecal samples originating from healthy cats in 3 geographically distinct multi-cat environments. One of those samples was detected only by immunofluorescence staining. This higher sensitivity can be explained by the use of more inoculum in that test. In the majority of the positive samples, infectious titres were always between $10^{3.05}$ to $10^{5.77}$ times lower compared to the total virus titre. This difference can be attributed to the presence of defective particles, but infectious titres in such faecal samples can possibly be underestimated due to faecal toxicity to the cells and the presence of neutralizing IgA antibodies as well. In infection experiments with FECV UCD, the amount of infectious particles was typically 3-4 $\log _{10}$ times lower compared to the total amount of particles in the first week pi, but this further increased thereafter most probably due to the generation of neutralizing antibodies (data not shown). It is impossible to estimate when cats in multi-cat environments became infected and the presence of neutralizing antibodies can explain why infectious virus in some of the faecal samples with a quite high viral load was not detectable. Coronavirus was detected in $3 / 4$ of the tested faecal samples from FIP cats. Previously, it has been shown that faecal viruses from FIP cats did not cause enteric infections or FIP upon inoculation of laboratory cats [18]. This can explain why, despite its high viral load, no infectious virus (neither in enterocytes nor in monocytes/macrophages) was found in the faeces of FIP cat 1 (UG-FF1). However, enterotropic 
virus was found in the faeces from another FIP cat (UG-FF2) that was housed in a Belgian shelter. To search for explanations for this discrepancy, accessory proteins of the virus in faecal and tissue suspensions of that cat were sequenced (data not shown). As in all faecally shed FCoVs sequenced so far $[18,32,35]$, the faecal strain carried an intact $3 \mathrm{c}$ gene. In addition, this strain showed only $96 \%$ and $89 \%$ homology with the tissue strain based on $7 \mathrm{a}$ and $7 \mathrm{~b}$ protein respectively. So it seems that this cat was co-infected with another, most probably enteric strain circulating in that shelter, explaining the shedding of enterotropic infectious virus in that cat. In 3/4 of the tissue samples from FIP cats (UG-TF5, UG-TF9 and UG-TF17), infectious virus was found by inoculation of monocyte-derived macrophages. However, these viruses seemed to have lost their tropism for intestinal epithelial cells since no infection was detected after inoculation of the intestinal epithelial cell cultures. The fact that FECV is the only pathotype that is well adapted for growth in intestinal epithelial cells shows that FECVs have the advantage over FIPVs to spread amongst cats. These findings are in agreement with previous observations on FCoV epidemiology, explaining the restricted transmission of FIPVs and hence low incidence of cats with FIP [6,16-18].

Since no cell culture-propagated serotype I enteric strains are available, two of those strains, FECV UCD and UG$\mathrm{FH} 8$, were further propagated in the established cultures. After 3 passages, both virus strains were raised in titre with $3 \log _{10}$ TCID $_{50} / \mathrm{mL}$, making them usable for further in vitro experiments. It has been described that the $7 \mathrm{~b}$ glycoprotein is not necessary for replication in cell cultures and hence this gene is readily lost by in vitro propagation. Therefore, alterations in the $7 \mathrm{~b}$ protein can be a sign for cell culture adaptation as seen in many of the cell culture propagated serotype I FIPVs [41]. In present study, no such signs of cell culture adaptation were detected for both $3^{\text {th }}$ passage strains, which still carried intact ORF7 genes identical to the original faecal strains. All field enteric strains sequenced so far carried intact $3 c$ genes $[18,32,35]$. To date, the only available avirulent, enteritis-inducing strain, WSU 79-1683, has a mutated 3c gene and for that reason doubt has been cast on the use of this strain as a typical enteric pathotype $[17,40]$. Both FECV UCD and UGFH8 propagated in this study still carried an intact (and identical to the original strain) ORF3. In addition, the cell culture propagation of both strains did not extend their tropism to other non-enterocytic feline cells, making them useful as representatives of the enteric pathotype.

In conclusion, we established cultures of both feline small and large intestinal epithelial cells, providing new and reliable in vitro models for studying enteric pathogenesis processes of FCoVs. These enterocyte cultures were susceptible to different enteric serotype I field strains, while FIPVs were clearly restricted in their replication in intestinal epithelial cells. Two of the enteric strains were further propagated, providing relevant enteric strains for future FCoV research.

\section{Competing interests}

The authors declare that they have no competing interests.

\section{Authors' contributions}

LMBD participated in the design of the study, carried out cell isolation, characterization and immortalization processes, performed and analysed infection studies and drafted the manuscript. ST participated in the design and performance of cell isolation, characterization and real time RT-PCR procedures. DAJO participated in cell characterization and immortalization. AD helped in the design of real time RT-PCR procedures. BLV participated in statistical analysis and infection experiments. IDMR contributed in sequencing studies. HJN designed and coordinated the study, and contributed in the interpretation of data and the final version of the manuscript. All authors read and approved the final manuscript.

\section{Acknowledgements}

We are grateful to Dr Egberink and Dr Rottier for supplying the virus strains. We also acknowledge Ytse Noppe for her excellent technical support. We gratefully thank the vets, and particularly Laurent Pauwels, for the interaction with the owners of the cats and of course the owners as well for their contribution to this work. This research was funded by The Research Foundation-Flanders (FWO-Vlaanderen; G.0284.09 N). LMBD was supported by a doctoral fellowship of The Research Foundation-Flanders. DAJO, AD, BLV and IDMR were supported by the Institute for the Promotion of Innovation through Science and Technology in Flanders (IWT Vlaanderen).

Received: 27 February 2013 Accepted: 9 August 2013

Published: 21 August 2013

\section{References}

1. Meli M, Kipar A, Muller C, Jenal K, Gonczi E, Borel N, Gunn-Moore D, Chalmers S, Lin F, Reinacher M, Lutz H: High viral loads despite absence of clinical and pathological findings in cats experimentally infected with feline coronavirus (FCoV) type I and in naturally FCoV-infected cats. J Feline Med Surg 2004, 6:69-81.

2. Kipar A, Meli ML, Baptiste KE, Bowker L, Lutz H: Sites of feline coronavirus persistence in healthy cats. J Gen Virol 2010, 91:1698-1707.

3. Pedersen NC, Boyle JF, Floyd K, Fudge A, Barker J: An enteric coronavirus infection of cats and its relationship to feline infectious peritonitis. Am J Vet Res 1981, 42:368-377.

4. Hayashi T, Watabe $Y$, Nakayama H, Fujiwara K: Enteritis due to feline infectious peritonitis virus. Nihon Juigaku Zasshi 1982, 44:97-106.

5. Herrewegh AA, Mahler M, Hedrich HJ, Haagmans BL, Egberink HF, Horzinek MC, Rottier PJ, de-Groot RJ: Persistence and evolution of feline coronavirus in a closed cat-breeding colony. Virology 1997, 234:349-363.

6. Addie $\mathrm{DD}$, Jarrett O: Use of a reverse-transcriptase polymerase chain reaction for monitoring the shedding of feline coronavirus by healthy cats. Vet Rec 2001, 148:649-653.

7. Stoddart ME, Gaskell RM, Harbour DA, Pearson GR: The sites of early viral replication in feline infectious peritonitis. Vet Microbiol 1988, 18:259-271.

8. Addie DD, Jarrett $\mathrm{O}$ : A study of naturally occurring feline coronavirus infections in kittens. Vet Rec 1992, 130:133-137.

9. Rottier PJ, Nakamura K, Schellen P, Volders H, Haijema BJ: Acquisition of macrophage tropism during the pathogenesis of feline infectious peritonitis is determined by mutations in the feline coronavirus spike protein. J Virol 2005, 79:14122-14130.

10. Dewerchin $\mathrm{HL}$, Cornelissen $\mathrm{E}$, Naumynck $\mathrm{HJ}$ : Replication of feline coronaviruses in peripheral blood monocytes. Arch Virol 2005, 150:2483-2500.

11. Vennema H, Poland A, Foley J, Pedersen NC: Feline infectious peritonitis viruses arise by mutation from endemic feline enteric coronaviruses. Virology 1998, 243:150-157.

12. Stoddart CA, Scott FW: Intrinsic resistance of feline peritoneal macrophages to coronavirus infection correlates with in vivo virulence. J Virol 1989, 63:436-440. 
13. Kipar A, Bellmann S, Kremendahl J, Kohler K, Reinacher M: Cellular composition, coronavirus antigen expression and production of specific antibodies in lesions in feline infectious peritonitis. Vet Immunol Immunopathol 1998, 65:243-257.

14. Horzinek MC, Osterhaus AD: The virology and pathogenesis of feline infectious peritonitis. Brief review. Arch Virol 1979, 59:1-15.

15. Montali RJ, Strandberg JD: Extraperitoneal lesions in feline infectious peritonitis. Vet Pathol 1972, 9:109-121.

16. Addie DD, Toth $S$, Murray GD, Jarrett O: Risk of feline infectious peritonitis in cats naturally infected with feline coronavirus. Am J Vet Res 1995, 56:429-434.

17. Pedersen NC: A review of feline infectious peritonitis virus infection: 1963-2008. J Feline Med Surg 2009, 11:225-258.

18. Pedersen NC, Liu H, Scarlett J, Leutenegger CM, Golovko L, Kennedy H, Kamal FM: Feline infectious peritonitis: role of the feline coronavirus $3 c$ gene in intestinal tropism and pathogenicity based upon isolates from resident and adopted shelter cats. Virus Res 2012, 165:17-28.

19. Wolf $\mathrm{J}$ : The impact of feline infectious peritonitis on catteries. Feline Practice 1995, 23:21-23.

20. Fiscus SA, Teramoto YA: Antigenic comparison of feline coronavirus isolates: evidence for markedly different peplomer glycoproteins. J Virol 1987, 61:2607-2613.

21. Vennema $\mathrm{H}$ : Genetic drift and genetic shift during feline coronavirus evolution. Vet Microbiol 1999, 69:139-141.

22. Addie DD, Schaap IA, Nicolson L, Jarrett O: Persistence and transmission of natural type I feline coronavirus infection. J Gen Virol 2003, 84:2735-2744.

23. Hohdatsu T, Okada S, Ishizuka Y, Yamada H, Koyama H: The prevalence of types I and II feline coronavirus infections in cats. J Vet Med Sci 1992, 54:557-562.

24. Benetka V, Kubber-Heiss A, Kolodziejek J, Nowotny N, Hofmann-Parisot M, Mostl K: Prevalence of feline coronavirus types I and II in cats with histopathologically verified feline infectious peritonitis. Vet Microbiol 2004 99:31-42.

25. Kummrow M, Meli ML, Haessig M, Goenczi E, Poland A, Pedersen NC, Hofmann-Lehmann R, Lutz H: Feline coronavirus serotypes 1 and 2: seroprevalence and association with disease in Switzerland. Clin Diagn Lab Immunol 2005, 12:1209-1215.

26. Lin CN, Su BL, Wang CH, Hsieh MW, Chueh TJ, Chueh LL: Genetic diversity and correlation with feline infectious peritonitis of feline coronavirus type I and II: a 5-year study in Taiwan. Vet Microbiol 2009, 136:233-239.

27. Herrewegh AA, Smeenk I, Horzinek MC, Rottier PJ, de-Groot RJ: Feline coronavirus type II strains 79-1683 and 79-1146 originate from a double recombination between feline coronavirus type I and canine coronavirus. J Virol 1998, 72:4508-4514.

28. Lin CN, Chang RY, Su BL, Chueh LL: Full genome analysis of a novel type II feline coronavirus NTU156. Virus Genes 2012, 46:316-322.

29. McKeirnan AJ, Evermann JF, Davis EV, Ott RL: Comparative properties of feline coronaviruses in vitro. Can J Vet Res 1987, 51:212-216.

30. Pedersen NC, Evermann JF, McKeirnan AJ, Ott RL: Pathogenicity studies of feline coronavirus isolates 79-1146 and 79-1683. Am J Vet Res 1984 45:2580-2585

31. Tekes G, Spies D, Bank-Wolf B, Thiel V, Thiel HJ: A reverse genetics approach to study feline infectious peritonitis. J Virol 2012, 86:6994-6998.

32. Chang HW, de-Groot RJ, Egberink HF, Rottier PJ: Feline infectious peritonitis: insights into feline coronavirus pathobiogenesis and epidemiology based on genetic analysis of the viral $3 c$ gene. $J$ Gen Virol 2010, 91:415-420.

33. Chang HW, Egberink HF, Halpin R, Spiro DJ, Rottier PJ: Spike protein fusion Peptide and feline coronavirus virulence. Emerg Infect Dis 2012, 18:1089-1095.

34. Chang HW, Egberink HF, Rottier PJ: Sequence analysis of feline coronaviruses and the circulating virulent/avirulent theory. Emerg Infect Dis 2011, 17:744-746.

35. Pedersen NC, Liu H, Dodd KA, Pesavento PA: Significance of coronavirus mutants in feces and diseased tissues of cats suffering from feline infectious peritonitis. Viruses 2009, 1:166-184.

36. Rusu D, Loret S, Peulen O, Mainil J, Dandrifosse G: Immunochemical, biomolecular and biochemical characterization of bovine epithelial intestinal primocultures. BMC Cell Biol 2005, 6:42.

37. Reed $\mathrm{L}$, Muench $\mathrm{H}$ : A simple method for estimating fifty percent endpoints. Am J Hyg 1938, 27:493-497.
38. Kaeffer B: Mammalian intestinal epithelial cells in primary culture: a mini-review. In Vitro Cell Dev Biol Anim 2002, 38:123-134.

39. Baer PC, Bereiter-Hahn J: Epithelial cells in culture: injured or differentiated cells? Cell Biol Int, in press.

40. Pedersen NC, Allen CE, Lyons LA: Pathogenesis of feline enteric coronavirus infection. J Feline Med Surg 2008, 10:529-541.

41. Herrewegh AA, Vennema H, Horzinek MC, Rottier PJ, de-Groot RJ: The molecular genetics of feline coronaviruses: comparative sequence analysis of the ORF7a/7b transcription unit of different biotypes. Virology 1995, 212:622-631.

doi:10.1186/1297-9716-44-71

Cite this article as: Desmarets et al: Establishment of feline intestinal epithelial cell cultures for the propagation and study of feline enteric coronaviruses. Veterinary Research 2013 44:71.

\section{Submit your next manuscript to BioMed Central and take full advantage of:}

- Convenient online submission

- Thorough peer review

- No space constraints or color figure charges

- Immediate publication on acceptance

- Inclusion in PubMed, CAS, Scopus and Google Scholar

- Research which is freely available for redistribution

Submit your manuscript at www.biomedcentral.com/submit
C BioMed Central 